\title{
Metastatic Bladder Small Cell Carcinoma
}

National Cancer Institute

\section{Source}

National Cancer Institute. Metastatic Bladder Small Cell Carcinoma. NCI Thesaurus. Code C157763.

Bladder small cell neuroendocrine carcinoma that has spread to another anatomical site. 